\title{
Effect of the Maillard Reaction on the Attributes of Egg White Proteins
}

\author{
Yasuko Kato, Kenji Watanabe* and Yasushi Sato* \\ Women's College of Tokaigakuen, Tenpaku-ku, Nagoya 468, Japan \\ * Faculty of Agriculture, Nagoya University, \\ Chikusa-ku, Nagoya 464, Japan
}

Received May 11, 1978

\begin{abstract}
Egg white solids freeze-dried with or without the addition of glucose were stored at $50^{\circ} \mathrm{C}$ under $65 \%$ relative humidity to study the effect of the Maillard reaction on the solubility and heat stability and the formation of aggregates. A stimulative effect on the former properties was observed on the sample with glucose in the initial stage of the Maillard reaction. By comparing the SDS-polyacrylamide gel electrophoretic patterns, solubilities in SDS and SDS/2mercaptoethanol and the $s_{20, w}$ values, it was found that glucose, in addition to the effect due to the changes of charged groups in glucose-protein complex occurring in the course of the Maillard reaction, might have a protective effect against aggregate formation through a stable cross-linking, which was not dependent on the SS bond, and through a stable non-covalent bond.
\end{abstract}

The Maillard reaction between several kinds of reducing sugar and proteins in food has been investigated from various standpoints, and comprehensively reviewed by many workers. ${ }^{1 \sim 3)}$ Since the physico-chemical and chemical properties of the food proteins change as a result of the Maillard reaction, some problems arise to the functional properties and nutritive value of food. Classically, it was reported that the proteins lose much of their solubility during the course of the Maillard reaction. ${ }^{4,5}$ However, Tybor et al. ${ }^{6}{ }^{7}$ and Morales et al. ${ }^{7}$ demonstrated that the complexing of serum proteins with lactose or glucose increased the stability and solubility of the proteins in the initial stage of the Maillard condensation. Solubility is an important factor to other functional properties, such as emulsifying capacity, of protein. ${ }^{8)}$

In order to obtain further information on the properties of the protein-glucose complex, we studied changes in chemical and physicochemical properties, such as solubility and heat stability, during the storage of egg white solid freeze-dried with or without the addition of glucose, and also the aggregation of proteins which is an important responsible factor for these changes.

\section{MATERIALS AND METHODS}

Sample preparation. Egg white, obtained from a strain of White Leghorn layers within $24 \mathrm{hr}$ after laying, was homogenized with care not to allow foaming, adjusted to $\mathrm{pH} 10$ with $0.1 \mathrm{~N} \mathrm{NaOH}$ because browning reaction could be promoted at a higher $\mathrm{pH}$.level, ${ }^{\text {, }}$ ? and freeze-dried (sample: EWS). The mixture of egg white with D-glucose, corresponding to $30 \%$ of the dry weight of the egg white, was treated by the same procedure as above (sample: EWSG). EWS and EWSG contained free glucose corresponding to $3.0 \%$ and $25.4 \%$ of the dry weights of the respective samples. Both samples were then stored in uncapped $20 \mathrm{ml}$ glass vials in sealed chambers at $50^{\circ} \mathrm{C}$. The relative humidity (R.H.) inside the chambers at $50^{\circ} \mathrm{C}$ was kept constant at $65 \%$ with supersaturated potassium iodide solution.

Browning color measurement. The extent of browning was measured at $420 \mathrm{~nm}$ with a Shimadzu spectrophotometer (type UV-200S), using 1\% solution (w/v) as a protein content of each of the unstored and stored EWS and EWSG.

Free amino groups. The unstored and stored EWS and EWSG were suspended at a level of $1 \%(w / v)$ in $\mathrm{pH} 10$ carbonate buffer $(I=0.1)$, soaked for $1 \mathrm{hr}$ and homogenized with a flash mixer. After being diluted 10 times with $4 \% \mathrm{NaHCO}_{3}$, the solutions were used as samples for free amino group determination by the method of Kakade and Liener (1969). ${ }^{10)}$

Solubility measurements. Solubility was estimated by the following three methods: 1) To measure the 
effect of $\mathrm{pH}$ on solubility, each of the unstored and $38 \mathrm{hr}$-stored EWS and EWSG was suspended at a level of $10 \%(\mathrm{w} / \mathrm{v})$ in a protein content in $\mathrm{pH} 4,5,6,7,8,9$ and 10 buffers containing $2 \mathrm{M} \mathrm{NaCl}(\mathrm{pH} 4$ and 5 : acetate buffer, $\mathrm{pH} 6,7$ and 8 phosphate buffer, pH 9 and 10: carbonate buffer), soaked for $1 \mathrm{hr}$ and centrifuged at $3000 \mathrm{rpm}$ for $15 \mathrm{~min}$. 2) To measure the effect of the length of storage on solubility, the unstored and stored samples of EWS and EWSG were suspended at a level of $10 \%(\mathrm{w} / \mathrm{v})$ in $\mathrm{pH} 4.8$ citrate buffer containing $2 \mathrm{M} \mathrm{NaCl}$, soaked and centrifuged as specified in 1). 3) To determine the occurrence of aggregates, the samples used in the procedure of 2 ) were suspended at a level of $1 \%(\mathrm{w} / \mathrm{v})$ in $\mathrm{pH} 7.0$ phosphate buffer $(I=0.1)$, $3 \%$ sodium dodecyl sulphate (SDS) and $3 \% \operatorname{SDS} / 1 \%$ 2-mercaptoethanol, soaked and centrifuged as specified in 1). Soluble protein in each supernatant fraction was determined by the method of Lowry et al. ${ }^{11)}$ (1951) and/or micro-Kjeldahl.

Heat stability and turbidity. Heat stability was expressed in term of solubility by a modification of Morales et al..$^{7}$ as described below. The unstored and stored EWS and EWSG were suspended at a level of $1 \%(\mathrm{w} / \mathrm{v})$ in citrate buffer $(\mathrm{pH} 6.0)$ containing $2 \mathrm{M} \mathrm{NaCl}$. The solution were heated at $70^{\circ} \mathrm{C}$ for $5 \mathrm{~min}$, cooled to $20^{\circ} \mathrm{C}$ immediately afterwards and centrifuged at $3000 \mathrm{rpm}$ for $15 \mathrm{~min}$. The turbidity of the supernatant was measured at $660 \mathrm{~nm}$, and the soluble protein content was measured as described above.

SDS-polyacrylamide gel electrophoresis. The samples were dissolved in SDS- or SDS $1 \%$ 2-mercaptoethanol- Tris-HCl buffer (pH 8.9) (SDS: five times as much as protein). SDS-polyacrylamide gel electrophoresis was carried out in $5 \%$ polyacrylamide gel in the presence of $0.5 \% \mathrm{SDS}$, and the gels were stained for proteins with amide black 10B. A Shimadzu dualwavelength scanner, Model CS-910, was used to obtain absorbance tracings. The molecular and particle weight were estimated by comparing mobility with those of standard proteins run concurrently in another gel, as described by Wever and Osborn (1969). ${ }^{12}$

Ultracentrifugal analysis. Ultracentrifugal analysis was accomplished with a Hitachi Model UCA-1A analytical ultracentrifuge. Double sector center pieces were used in an RA-60 rotor at a rotor speed of 51200 rpm at $20^{\circ} \mathrm{C}$. The filtrate obtained from the suspension of phosphate buffer $(\mathrm{pH} 7.0, I=0.1)$ at a level of $1 \%$ $(w / v)$ was run. $S$ values are reported as equivalents at $20^{\circ} \mathrm{C}$ and in water.

\section{RESULTS AND DISCUSSION}

Browning color development and loss of free amino groups during storage are traced

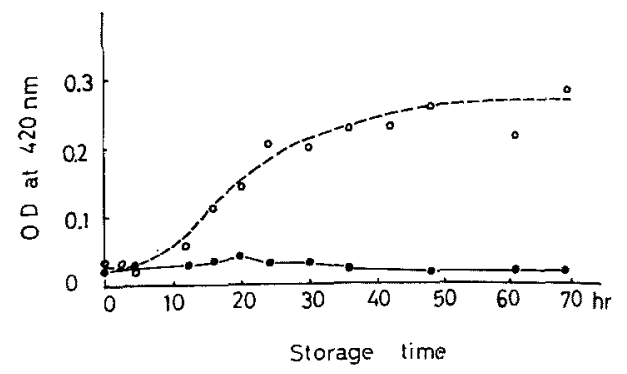

FIG. 1. Browning Color Development of the Freezedried Egg White and Egg White-Glucose Solids.

-, egg white solid; 0 , egg white-glucose solid.

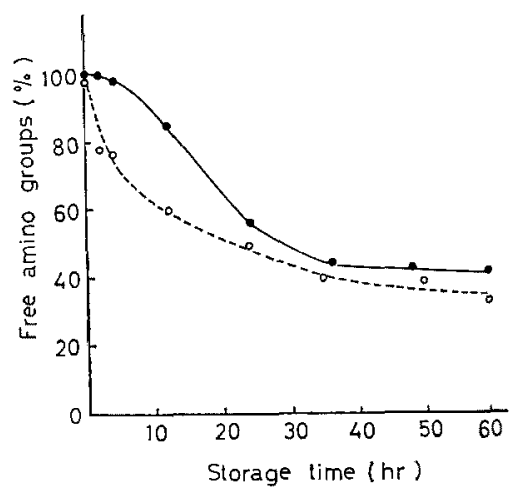

Frg. 2. Changes in Free Amino Group Contents.

•, egg white solid; $\bigcirc$, egg white-glucose solid.

in Figs. 1 and 2, respectively. The brown color development in EWSG had an induction period during the first $10 \mathrm{hr}$ and then a rise for about $25 \mathrm{hr}$ followed by constancy, but no browning discoloration in EWS was found during $68 \mathrm{hr}$ of observation. The loss of free amino groups occurred at a little faster rate in the samples of EWSG than in those of EWS. Fifty-two percent and $42 \%$ of the free amino groups interacted with glucose within the first $24 \mathrm{hr}$ of storage in EWSG and EWS, respectively, and about $60 \%$ reductions in free amino groups were measured in both samples after $60-\mathrm{hr}$ storage. It is interesting to note that the rate of color development did not correlate with the change in amounts of free amino groups.

The $\mathrm{pH}$ dependent solubilities of unstored and $38 \mathrm{hr}$-stored EWS and EWSG are presented in Fig. 3. The minimum solubilities in both unstored samples were obtained near pH 6 , the isoelectric point of conalbumin, and 


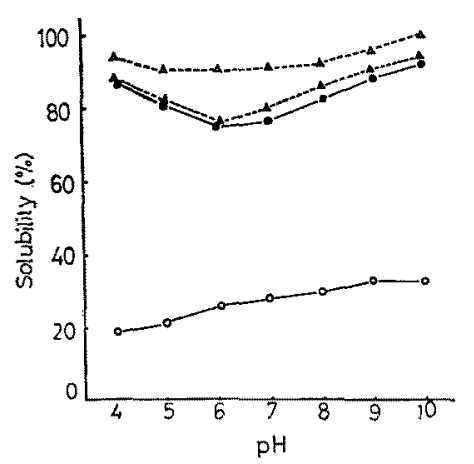

FIG. 3. Solubility in Each $\mathrm{pH}$ Buffer Solution.

Solubility is expressed in percentage of soluble protein to that of total protein content. 9 , egg white solid unstored; $O$, egg white solid stored for $38 \mathrm{hr} ; \Delta$, egg white-glucose solid unstored, $\triangle$, egg white-glucose solid stored for $38 \mathrm{hr}$.

their curves showed almost the same profiles, although the solubility was slightly higher in EWSG than in EWS. On the other hand, the stored EWSG and EWS indicated the highest and lowest solubilities with an about $80 \%$ difference between the two curves throughout the $\mathrm{pH}$ range studied. The solubility in the stored EWSG was also slightly higher than that in the unstored.

As can be seen from Fig. 4 in which the changes in solubility during storage are followed, the solubilities of EWSG were more than

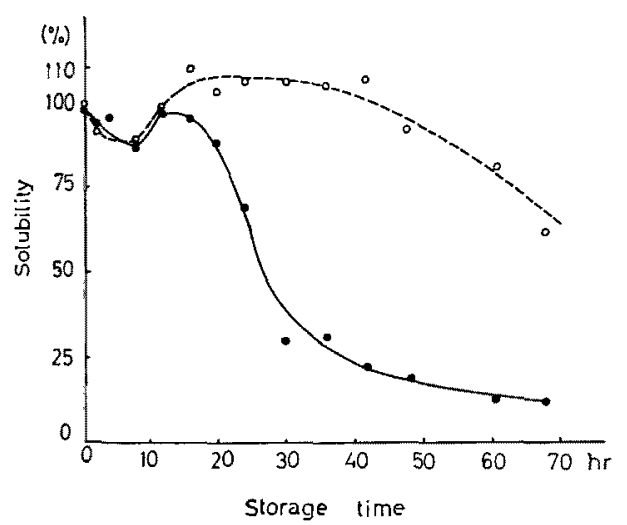

Frg. 4. Solubility in Citrate Buffer Containing $2 \mathrm{M}$ $\mathrm{NaCl}(\mathrm{pH} 6.0)$ of the Freeze-dried Egg White and Egg White-Glucose Solids.

Solubility is expressed in percentage of soluble protein to that of unstored egg white. e, egg white solid; O, egg white-glucose solid.
$100 \%$ in storage for 12 to $40 \mathrm{hr}$ (its maximum concentration: $100 \mathrm{mg} / \mathrm{ml}$ ), and then decreased to about $62 \%$ in 68 -hr storage. In contrast, those of EWS decreased abruptly to about $20 \%$ of the original value in storage for 16 to $40 \mathrm{hr}$ and then slowly to $13 \%$ in $68 \mathrm{hr}$ storage. Both samples reached their respective minima of solubility, very low levels, in $8 \mathrm{hr}$. The changes in soluble amounts of protein did not correspond to the loss of free amino groups. So, it can be said that the increase in solubility was due to the complexing products of egg white protein with glucose and the presence of residual glucose in the reacted system.

The changes during storage in heat stability and turbidity of EWS and EWSG are diagrammed in Fig. 5. The phenomenon that the heat stability indicated a smaller minimum in storage for $2 \sim 4 \mathrm{hr}$ was similar to that in Fig. 4. Precipitation after heating did not occur in EWSG till 42-hr storage. However, after that the heat stability began to decrease and fell off to $58 \%$ in $72 \mathrm{hr}$. On the other hand, EWS was also stable on heat treatment in the rage of 4 to $16 \mathrm{hr}$, followed by a rapid decrease in stability during further storage.

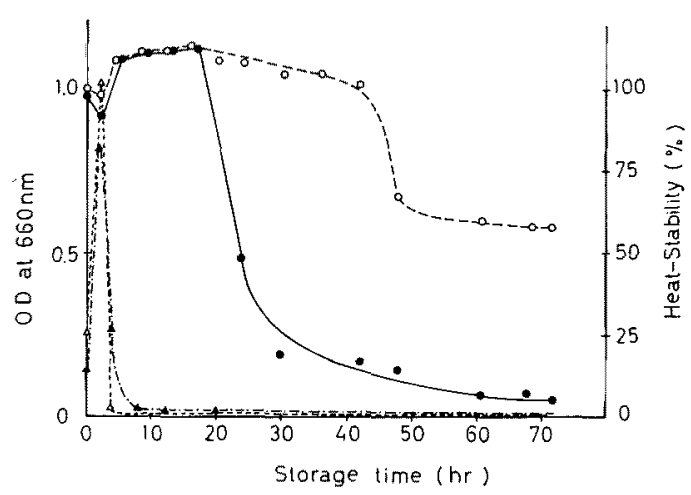

FIG. 5. Solubility and Turbidity in Citrate Buffer Containing $2 \mathrm{M} \mathrm{NaCl}(\mathrm{pH} 6.0$ ) of the Freeze-dried Egg White and Egg White-Glucose Solids after Heating at $70^{\circ} \mathrm{C}$ for $5 \mathrm{~min}$.

Solubility is expressed in percentage of soluble protein to that of unstored egg white. - solubility of egg white solid; $O$, solubility of egg white-glucose solid; $\Delta$, turbidity of egg white solid; $\Delta$, turbidity of egg white-glucose solid. 
Turbidity of the supernatant in both samples increased only when they were stored for 2 to $4 \mathrm{hr}$. It was demonsţrated in a previous work $^{13}$ ) that the charged groups of protein resulting from the blocking of $\varepsilon$-amino group had an important role in the protein-protein interaction, namely aggregation and coagulation. This demonstration, combined with the results on heat stability and turbidity described above, suggests that a part of protein in EWS and EWSG already began to denature in storage for the first $4 \mathrm{hr}$ and the denatured proteins were complexed with glucose and much solubilized, depending on the kind of products during the course of the Maillard concentration. The $\mathrm{NaCl}$ precipitation technique which had been used as a useful method for monitoring heat denaturation ${ }^{14)}$ might not reveal the denaturation ratio in the presence of a complex of protein and glucose, even though protein was denatured.

As shown in Fig. 6, proteins in EWS and EWSG stored for 0,24 and $40 \mathrm{hr}$ were separated into various bands by SDS, polyacrylamide gel electrophoresis. In Fig. 6-A-c and $\mathrm{d}$, bands corresponding to the dimer of ovalbumin (III in Fig. 6-A) and polymer (IV in

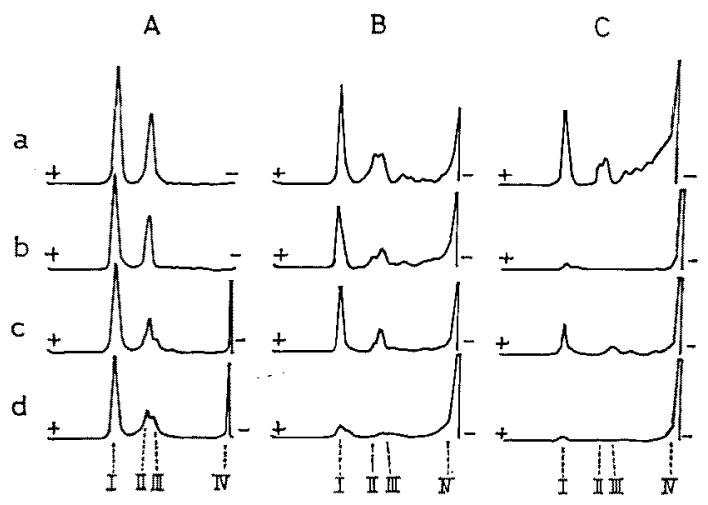

FIG. 6. SDS Polyacrylamide Gel Electrophoretic Pattern and Densitometric Tracing of Freeze-dried Egg White and Egg White-Glucose Solids.

A, unstored samples; B, 24-hr stored samples; C, 40-hr stored samples. Samples: a, c=egg whiteglucose solid, $b, d=$ egg white solid. Solvents : $a, b=$ SDS/2-mercaptoethanol, c, d=SDS. I, ovalbumin; II, conalbumin; III, dimer; IV, polymer.
Fig. 6-A) having much greater particle weights were observed in addition to ovalbumin (I in Fig. 6-A) and conalbumin (II in Fig. 6-A). These aggregates might be produced during the freezing and freeze-drying process through intermolecular SS bonds, because they were reduced monomers with 2-mercaptoethanol (Fig. 6-A-a and b). With the lapse of storage time, ovalbumin and conalbumin were taken into aggregates having greater particle weights which could not be reduced into monomers (Fig. 6-B and C). The ratio of polymerization was higher in EWS than in EWSG. Therefore, it is apparent that egg white proteins were protected against the aggregate forming effect of glucose. Further, the electrophoretic patterns after the reduction referred to in Fig. 6-B and $\mathrm{C}$ suggest that aggregates might be formed, especially in the samples of EWS, through stable covalent bond other than SS bond and through stable non-covalent bond, because they were not cleaved by SDS +2 -mercaptoethanol. Such a cross-linking in the former could be produced as a result of the Maillard reaction, regardless of the browning color development.

The solubilities of EWS and EWSG samples
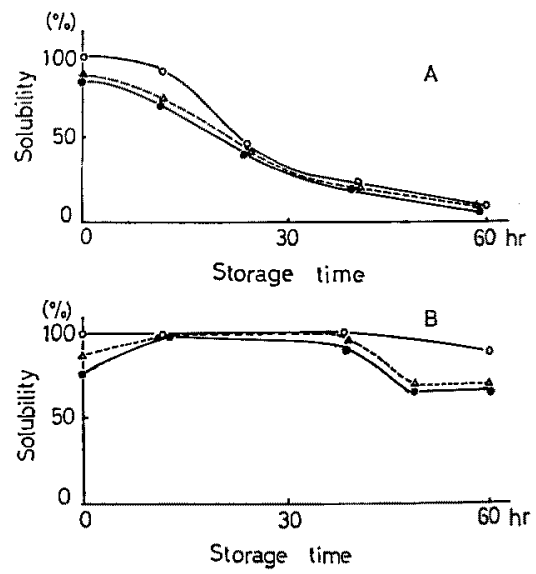

FIG. 7. Solubility in Phosphate Buffer ( $\mathrm{pH} \mathrm{7.0),3 \%}$ SDS and $3 \%$ SDS $/ 1 \%$ 2-Mercaptoethanol of the Freeze-dried Egg White and Egg White-Glucose Solids.

Solubility is expressed in percentage of soluble protein to that of total protein content. A, egg white solid; B, egg white-glucose solid; $\mathbf{O}$, phosphate buffer; $\triangle, 3 \%$ SDS $; 0,3 \%$ SDS $/ 1 \%$ 2-mercaptoethanol. 
using the three solvents were compared with each other (Fig. 7). Differences due to solvent were slight in EWS, except the higher solubility observed during the first $25 \mathrm{hr}$ on the sample solubilized with SDS/2-mercaptoethanol. A major difference between EWS and EWSG was also observed in the solubility for the SDS+2-mercaptoethanol after a prolonged storage, suggesting that stable cross-linkings and non-covalent bonds were formed to a much greater extent in the former than in the latter. This difference can also be explained by the electrophotograms (Fig. 6-B and C).

Upon analytical ultracentrifugation, the remaining soluble parts of EWS and EWSG showed only one diffusion peak. The $s_{20, w}$ values of unstored samples (Table I) were nearly in agreement with that of ovalbumin reported by Smith and Back. ${ }^{15}$ There were only little difference between the $s_{20, w}$ values of the unstored and $4 \mathrm{hr}$-stored EWSG. This probably indicates that the molecules of ovalbumin did not easily change their size and/or shape in the presence of glucose. Glucose added to egg white might have a protective effect against protein molecular configuration during short storage. However, with an increase in storage time, the $s_{20, \mathrm{w}}$ value became slightly higher in EWSG than in EWS, although the remaining soluble protein was smaller in EWS.

Thus, it could be said that the solubility and heat-stability of egg white protein increased in the initial stages of the Maillard reaction when egg white mixed with a large excess of glucose relative to the number of $\varepsilon$-amino groups was freeze-dried and stored at low humidity. The authors would like to stress that glucose, in addition to the effect due to the changes of charge groups in glucose-protein complex occurring in the course of the Maillard
Table I. $s_{20, w}$ Values of the Analytical UltraCentrifugation for the Soluble Parts of the Egg White AND Egg White-Glucose Solids

\begin{tabular}{lcccc}
\hline & \multicolumn{4}{c}{ Storage time (hr) } \\
\cline { 2 - 5 } & 2 & 4 & 24 & 40 \\
\hline Egg white solid & 2.68 & 3.41 & 3.39 & 3.35 \\
Egg white-glucose solid & 2.58 & 2.87 & 3.65 & 3.88
\end{tabular}

Solvent: phosphate buffer (pH 7.0, $I=0.1$ ).

reaction, might have a protective effect against aggregation through a stable cross-linking and a stable non-covalent bond, in contrast to EWS.

\section{REFERENCES}

1) J. E. Hodge, J. Agric. Food Chem., 1, 928 (1953).

2) H. D. Lightbody and H. L. Fevold, $A d v$. Food Res., 1, 149 (1948).

3) S. T. Coulter, R. Jenness and W. F. Geddes, ibid., 3, 45 (1951).

4) A. Mohammad, H. Fraenkel-Conrat and H. S. Olcott, Arch. Biochem., 24, 157 (1949).

5) C. H. Lea, R. S. Hannan and D. N. Rhodes, Biochim. Biophys. Acta, 7, 366 (1951).

6) P. T. Tybor, C. W. Dill and W. A. Landmann, J. Food Sci., 38, 4 (1973).

7) M. Morales, C. W. Dill and W. A. Landmann, ibid., 41, 234 (1976).

8) A. M. Pearson, M. E. Spooner, G. R. Hegarty and L. J. Bratzler, Food Technol., 19, 1841 (1965).

9) S. Kato, N. Yano, I. Suzuki, T. Ishii, T. Kurata and M. Fujimaki, Agric. Biol. Chem., 38, 2425 (1974).

10) M. L. Kakade and I. E. Liener, Anal. Biochem., 27, 273 (1969).

11) O. H. Lowry, N. J. Rosebrough, A. L. Farr and R. L. Randall, J. Biol. Chem., 193, 265 (1951).

12) K. Weber and M. Osborn, ibid., 244, 4406 (1969).

13) Y. Sato and R. Nakamura, Agric. Biol. Chem., 41, 2163 (1977).

14) P. T. Tybor, C. W. Dill, J. N. Bryant and W. A. Landmann, J. Agric. Food Chem., 18, 629 (1970).

15) M. B. Smith and J. F. Back, Aust. Biol. Sci., 18, 365 (1965). 